\title{
Clinical spectrum, treatment and outcomes of uveal melanoma in a tertiary centre
}

Wendy Wong $^{1}$, MBBS, MMed, Gangadhara Sundar ${ }^{1}$, FRCSEd, FAMS, Caroline Chee $^{1}$ FRCSed, FRCophth, Paul Songbo $\underline{\text { Zhao }}^{1}$, MRCSEd, MMed, Rajesh Rajagopalan' ${ }^{2}$, FRCSEd, Lingam Gopal ${ }^{1,3}$, MS, FRCSEd

INTRODUCTION We aimed to describe the clinical characteristics, diagnostic challenges, treatment patterns and outcomes of uveal melanoma (UM) in a tertiary care centre.

METHODS This is a retrospective case series of 11 consecutive patients with UM who were managed in a tertiary referral centre between 2002 and 2017. Epidemiological, clinical, pathological and radiological characteristics were reviewed. Classification of choroidal melanoma as small, medium or large was based on the criteria established by the Collaborative Ocular Melanoma Study.

RESULTS Mean age at presentation was 42.9 (range 27-67) years. In 7 (64\%) patients, a definitive diagnosis of UM was made after a mean follow-up period of 6.4 (range 1-17) months. There were one, six and four patients with small-, medium- and large-sized choroidal melanomas, respectively. Treatment was enucleation in 5 (45.5\%) patients, plaque brachytherapy in $4(36.4 \%)$ patients, transpupillary thermotherapy in 1 (9.1\%) patient, and observation in 1 (9.1\%) patient. Median follow-up was 29 months. Metastatic disease developed in 5 (45.5\%) patients at the mean age of 46.6 (range 38-56) years, with median overall survival of 20 months. Genetic mutations in three patients were monosomy 3 $(n=2)$, and gain of $3 q$ and $8 q(n=1)$.

CONCLUSION Our study supports the finding that UM in Chinese and Asian Indian patients presents at a younger age than in Caucasians. Although it is rare, ophthalmologists should remain mindful of this life-threatening disease. We propose establishing a national and regional registry for ocular tumours with genetic information to characterise the disease spectrum in Southeast Asia.

Keywords: cytogenetics, metastasis, ocular oncology, uveal melanoma

\section{INTRODUCTION}

Uveal melanoma (UM) is an aggressive intraocular malignancy, and despite advances in the local methods of treatment of primary UM, the survival rates have not improved. ${ }^{(1)}$ This is thought to be due to the tumour's proclivity for early occult micro-metastasis, which is undetectable at the time of diagnosis and treatment of the primary tumour. ${ }^{(2,3)}$ At present, there are no effective chemotherapeutic agents for metastatic $U M^{(3)}$ with death rates from melanoma-related metastasis at $80 \%$ at one year and $92 \%$ at two years. ${ }^{(4)}$

The most common primary intraocular tumour in Caucasian adults is UM. The reported age-standardised incidence rate in the United States and Europe is 5.1 per million ${ }^{(5)}$ and 2.6-7.5 per million, respectively. In contrast, the age-standardised incidence rate in South Korea and Japan is 0.6 per million ${ }^{(6)}$ and 0.2 per million, ${ }^{(7)}$ respectively. The literature on the clinicopathologic spectrum of UM is largely derived from a Western setting. In the Collaborative Ocular Melanoma Study (COMS), as well as a more recently published series of 8,100 patients with UM, 97\%-98\% of patients were Caucasian, with Asian patients representing $<1 \%$ of patients in both cohorts. ${ }^{(8,9)}$

Aside from significant epidemiological heterogeneity, there is also marked biological diversity in UM. In recent years, the genetic abnormalities in UMs have been found to be distinct from those in cutaneous melanomas. In contrast to cutaneous melanomas, UMs lack mutations in B rapidly accelerated fibrosarcoma (BRAF), neuroblastoma rapidly accelerated sarcoma (NRAS) and Kit genes. ${ }^{(2,10)}$ Instead, mutations in guanine nucleotide-binding protein subunit alpha-Q (GNAQ) and guanine nucleotide-binding protein subunit alpha-11 (GNA11) are early events in UM tumorigenesis. BRCA1 associated protein-1 (BAP1) is implicated in tumour progression and metastasis. ${ }^{(11)}$ The cytogenetic profiles in UMs based on normal disomy 3, 6, 8, or partial/complete monosomy 3, 6p gain/loss, 6q gain/loss, $8 \mathrm{p}$ gain/loss, and $8 \mathrm{p}$ gain/loss have also been found to be predictive of the risk of melanoma-related metastasis. ${ }^{(12)}$

Our study reports the clinical characteristics, treatment patterns and outcomes of patients with UM treated in a tertiary centre in Southeast Asia.

\section{METHODS}

Patients with a diagnosis of UM made by clinical and/or pathologic analysis and who were followed up in our centre between 2002 and 2017 were retrospectively reviewed. Information on the patients' baseline demographics, clinical presentation, treatment and survival outcomes was collected. Approval from our Institutional Review Board was obtained.

Choroidal melanoma (CM) was classified as small, medium or large based on the criteria established by the COMS. A melanoma

\footnotetext{
${ }^{1}$ Department of Ophthalmology, National University Hospital, National University of Singapore, ${ }^{2}$ National Healthcare Group Eye Institute, Tan Tock Seng Hospital, Singapore, ${ }^{3}$ Medical Research Foundation, Sankara Nethralaya, Chennai, India

Correspondence: Dr Gangadhara Sundar, Senior Consultant and Head, Orbit and Oculofacial Surgery, Department of Ophthalmology, National University Hospital, National University of Singapore, 1E Kent Ridge Road, Singapore 119228. gangadhara_sundar@nuhs.edu.sg
} 
measuring 1.0-3.0 $\mathrm{mm}$ in apical height and at least $5.0 \mathrm{~mm}$ in basal diameter was classified as small. ${ }^{(13)} \mathrm{A}$ melanoma that was $3.1-10.0 \mathrm{~mm}$ in apical height and no more than $16.0 \mathrm{~mm}$ in largest basal diameter was classified as medium (the lower and upper limits on apical height were $3.1 \mathrm{~mm}$ and $8.0 \mathrm{~mm}$, respectively, until November 1990). ${ }^{(14,15)}$ A melanoma $>10.0 \mathrm{~mm}$ in apical height or $16.0 \mathrm{~mm}$ in diameter at the base, as well as a melanoma 8.0-10.0 $\mathrm{mm}$ in apical height but too close to the optic nerve for radioactive plaque therapy to be feasible, was classified as large. ${ }^{15}$

For patients with metastatic disease, overall survival from occurrence of metastases (metOS) was measured from the date of diagnosis of metastatic disease to date of death, or date of last follow-up for surviving patients.

\section{RESULTS}

A total of 11 patients (six male; five female) with CM were seen in the Oculoplastic/Ophthalmic Oncology Clinic during the 15-year study period. Table I summarises the baseline clinicopathologic characteristics of the patients.
The mean and median age at initial presentation was 42.9 (range 27-67) years and 40.0 years, respectively. The most common presenting symptom was blurring of vision ( $n=9,81.8 \%)$ and the most frequent finding was the presence of an elevated mass ( $n=7,63.6 \%$ ). There was one patient with small CM, six patients with medium $\mathrm{CM}$, and four patients with large $\mathrm{CM}$. Median tumour thickness and median largest basal diameter were $8 \mathrm{~mm}$ (range 2.8-24 mm) and $15 \mathrm{~mm}$ (range 4.5-20.0 mm), respectively.

In seven patients, the diagnosis was not made at first examination but subsequently, after a mean follow-up period of 6.4 (range 1-17) months. The preliminary diagnoses were as follows: possible rhegmatogenous retinal detachment, although retinal breaks were not observed $(n=2)$; choroidal naevus $(n=2)$; choroidal haemangioma $(n=1)$; neovascular glaucoma of uncertain origin $(\mathrm{n}=1)$; and choroidal haemorrhage with breakthrough vitreous haemorrhage $(n=1)$. Definitive treatment after final clinical diagnosis consisted of enucleation in 5 (45.5\%) patients, plaque brachytherapy in 4 (36.4\%) patients, transpupillary thermotherapy in $1(9.1 \%)$ patient, and observation in $1(9.1 \%)$ patient.

Table I. Clinicopathologic characteristics of patients with uveal melanoma $(n=11)$.

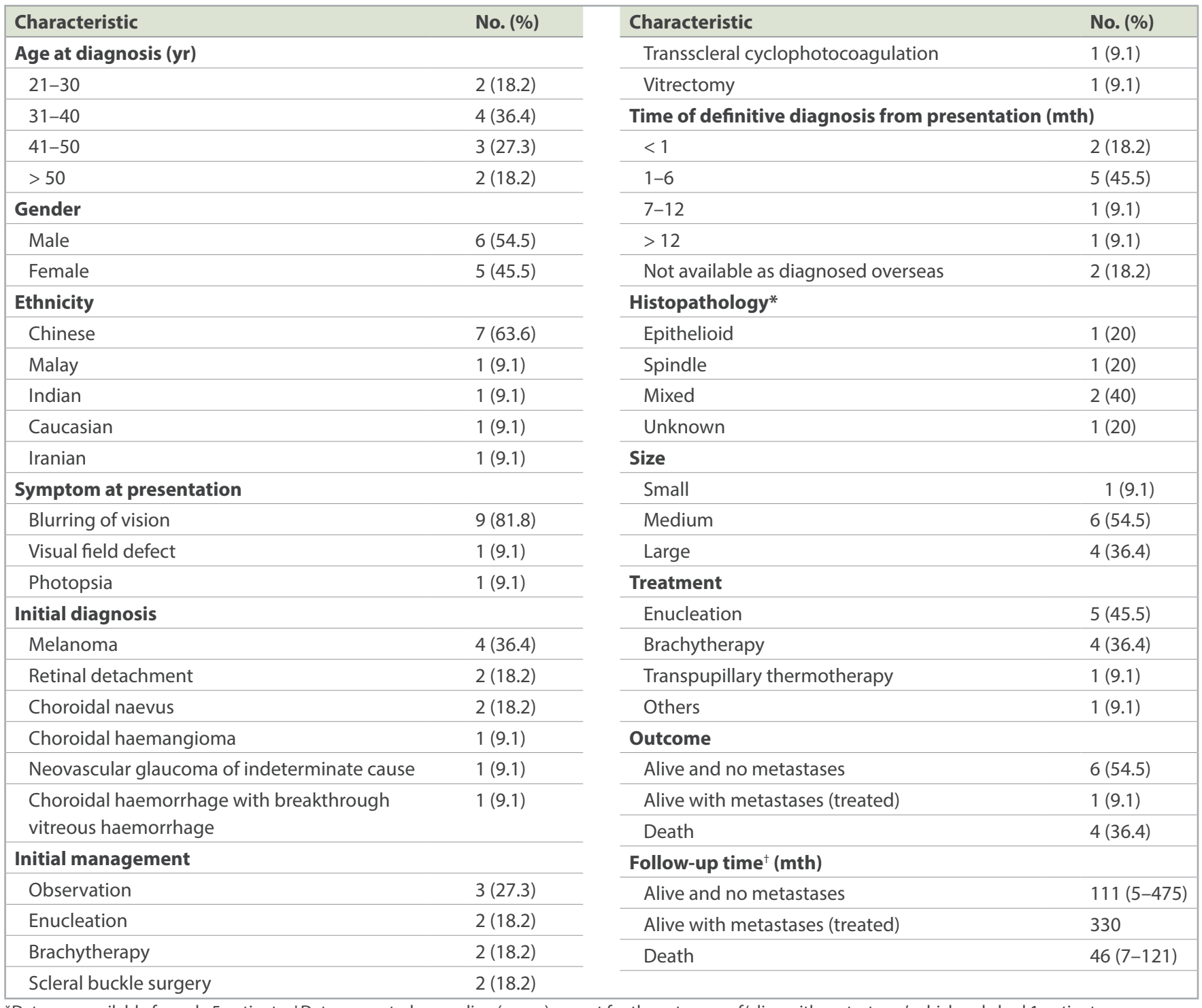

*Data was available for only 5 patients. †Data presented as median (range) except for the category of 'alive with metastases', which only had 1 patient. 
Of the four patients treated with brachytherapy, two patients had a residual tumour mass that remained stable with no sign of activity or growth during follow-up, following initial tumour regression. Radiation retinopathy developed in two patients, and they were treated with intravitreal injections of antivascular endothelial growth factor. One patient was treated with intravitreal bevacizumab (Avastin () ) and the other was treated with intravitreal ranibizumab (Lucentis®).

Metastatic disease developed in $5(45.5 \%)$ patients at the mean age of 46.6 (range 38-56) years. The mean time from diagnosis to detection of metastasis was 79.6 (range 0-267) months. Median metOS was 20 months. The clinical characteristics are summarised in Table II. One patient who presented with neovascular glaucoma had extensive hepatic metastasis at diagnosis (Fig. 1). In two patients, melanoma-related metastases developed within 24 months of a negative workup for metastatic disease at initial diagnosis. The first patient (Patient 2, Table III), who underwent a needle biopsy prior to enucleation, was diseasefree until 20 months postoperatively when she presented with extensive conjunctival pigmentation and liver metastasis (Fig. 2). Genetic testing revealed monosomy 3 and CKIT mutations, and targeted treatment with imatinib (Glivec $($ ) ) was commenced for hepatic and peritoneal metastases. However, the patient succumbed to hepatic failure a month later. The other patient underwent ipilimumab $\left(\right.$ Yervoy $\left.{ }^{\circledR}\right)$ monoclonal antibody therapy and intrahepatic chemotherapy for hepatic metastasis, and survived for 20 months after metastatic disease developed. In the remaining two patients, distant metastases occurred eight and 12 years after primary enucleation. In the first patient, the cytomorphology was not discernible from the necrotic tumour. Disseminated abdominal disease occurred and overall survival was 22 months on adjuvant imatinib (Glivec $($ )). The second patient had spindle-type UM and developed late metastasis to the lung. Following pulmonary metastectomy, this is the only patient with metastatic disease who has survived to date.

Three patients underwent genetic testing - two after enucleation and one prior to brachytherapy. Monosomy 3 and CKIT mutations were identified in a patient with hepatic metastasis. In the other two patients, the mutations identified were monosomy 3 and gain of $3 q / 8 q$, and they remain under surveillance for metastatic disease.

Median follow-up was 29 (range 5-475) months. A total of $7(63.6 \%)$ patients were alive at the time of analysis. Of the four patients who died, all deaths were due to melanoma-related metastasis.

\section{DISCUSSION}

Our study supports the finding that UM in Chinese and Asian Indian patients presents, on average, more than a decade earlier than in Caucasians. Several studies have consistently shown that the mean age at presentation with UM in Caucasians is 58-60 years. ${ }^{(5,8,16)}$ In Asian Indian and Chinese patients, the mean age at presentation is $44-46$ years. ${ }^{(8,17-19)}$ However, the mean age at presentation is later in the South Koreans (54 years) ${ }^{(6)}$ and Japanese (63 years). ${ }^{(20)}$ These studies are summarised in Table II.
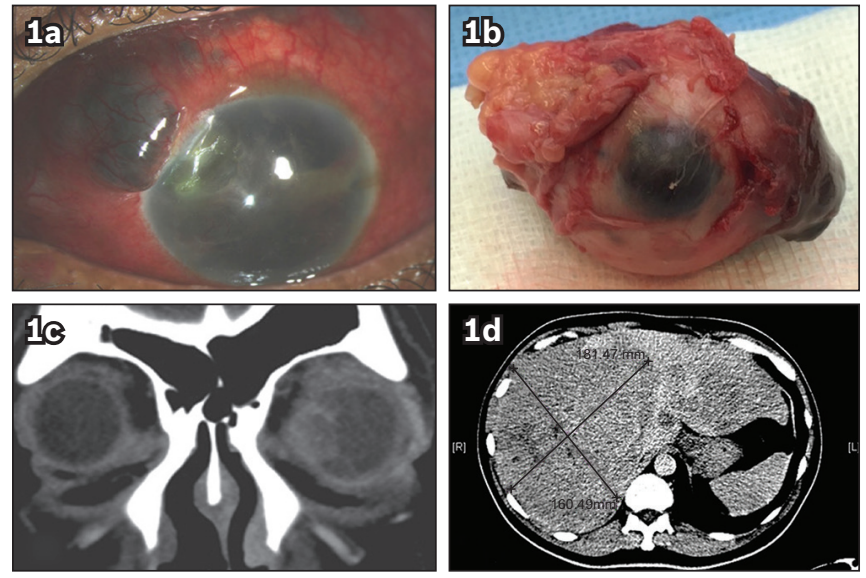

Fig. 1 (a) Photograph at presentation shows scleral thinning with staphyloma following transscleral cyclotherapy for neovascular glaucoma of indeterminate aetiology. (b) Photograph shows extended enucleation of a blind painful eye. CT images (c) prior to enucleation and (d) on workup show hepatic metastatic lesion; mortality occurred within one month.
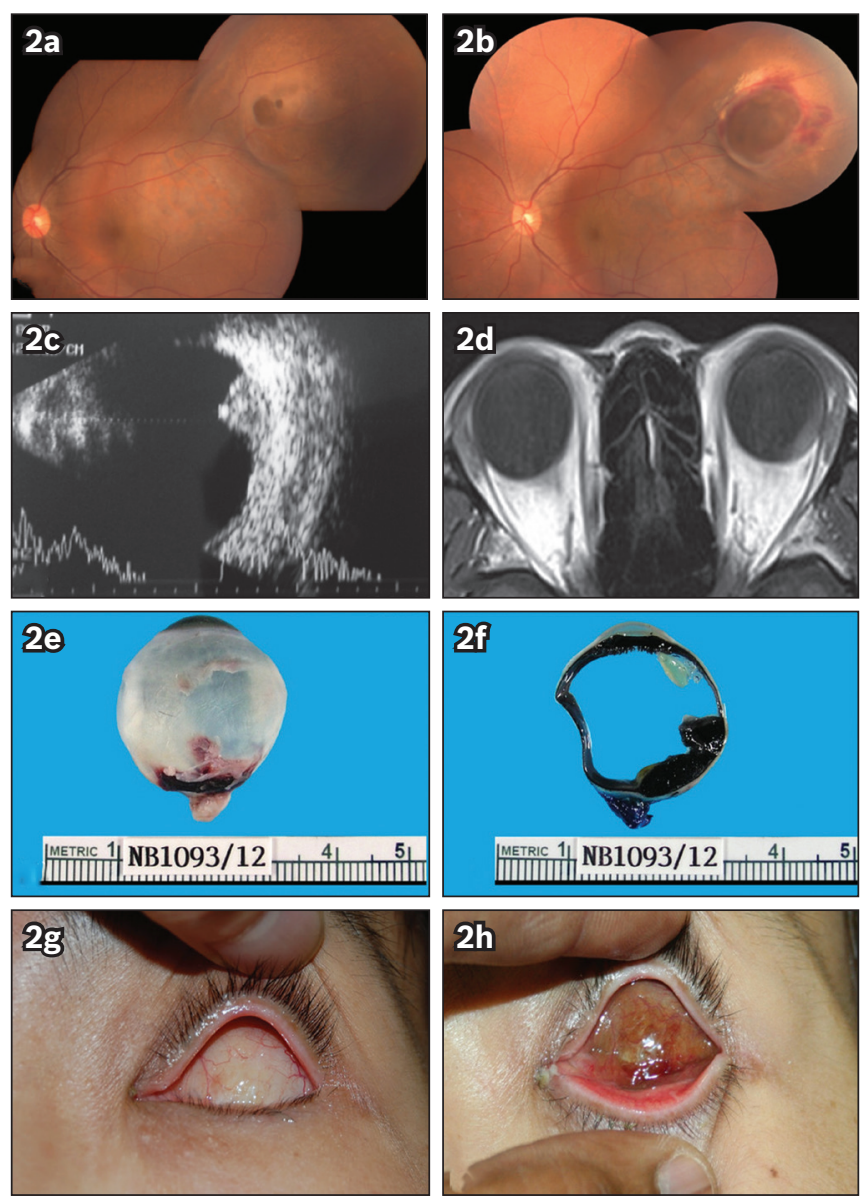

Fig. 2 Fundus photographs show (a) a post-equatorial double dome lesion and (b) documented progression over one week. (c) B-scan US image shows moderate-to-low reflectivity. (d) MR image of the orbits shows no extraocular extension of the tumour. Photographs show enucleation specimens of the (e) whole eye and (f) in cross-sectional view, with no extrascleral extension seen; and post-enucleation conjunctival pigmentation in $(g)$ early stage and $(h)$ late stage.

The reason that the Chinese and Asian Indians present with ocular melanoma at a younger age compared to other populations is still unclear, and this is of biological interest. We postulate that the earlier presentation could be due to differences in gene 
Table II. Summary of mean age at presentation of ocular melanoma in different study populations.

\begin{tabular}{|c|c|c|c|c|}
\hline Study; study period & No. of patients & Ocular melanoma (\%) & Ethnicity (\%) & Mean age at presentation (yr) \\
\hline $\begin{array}{l}\text { Shields et al; }{ }^{(8)} \\
1970-2008\end{array}$ & 8,100 & $\begin{array}{l}\text { Choroid (90) } \\
\text { CB (6) } \\
\text { Iris (4) }\end{array}$ & $\begin{array}{l}\text { Caucasian }(98) \\
\text { Hispanic }(1) \\
\text { Asian }(<1) \\
\text { African-American }(<1)\end{array}$ & $\begin{array}{l}58.0 \\
48.0 \\
44.0 \\
52.0\end{array}$ \\
\hline $\begin{array}{l}\text { Singh et al; }{ }^{(5)} \\
1973-2008\end{array}$ & 4,070 & $\begin{array}{l}\text { Choroid (65.2) } \\
\text { CB \& iris (14.6) } \\
\text { Others (20.2) }\end{array}$ & $\begin{array}{l}\text { Caucasian (97.8) } \\
\text { Others (2.2) }\end{array}$ & 62.0 \\
\hline $\begin{array}{l}\text { COMS }^{(9)} \\
1986-1994\end{array}$ & 1,003 & Choroid (100) & $\begin{array}{l}\text { Caucasian (97) } \\
\text { Hispanic (2) } \\
\text { Others (1) }\end{array}$ & 60.0 \\
\hline $\begin{array}{l}\text { Biswas et al; }{ }^{(17)} \\
\text { 1987-2001 }\end{array}$ & 103 & $\begin{array}{l}\text { Choroid (87.4) } \\
\text { CB \& iris (12.6) }\end{array}$ & Asian Indian (100) & 46.0 \\
\hline $\begin{array}{l}\text { Eskelin et al; }{ }^{(16)} \\
1994-1999\end{array}$ & 139 & Uveal (100) & Finnish (100) & 60.0 \\
\hline $\begin{array}{l}\text { Park et al, }{ }^{(6)} \\
\text { 1999-2011 }\end{array}$ & 464 & $\begin{array}{l}\text { Choroid (57.3) } \\
\text { CB \& iris (12.9) } \\
\text { Others (29.7) }\end{array}$ & South Korean (100) & 54.0 \\
\hline $\begin{array}{l}\text { Dhupper et al; }{ }^{(18)} \\
2000-2010\end{array}$ & 113 & Choroid (100) & Indian (100) & 46.0 \\
\hline $\begin{array}{l}\text { Liu et al;:(19) } \\
2005-2015\end{array}$ & 582 & $\begin{array}{l}\text { Choroid (94.2) } \\
\text { CB (5.7) } \\
\text { Iris }(0.2)\end{array}$ & Chinese (100) & 45.0 \\
\hline $\begin{array}{l}\text { Tomizuka et al; }{ }^{(20)} \\
2011-2013\end{array}$ & 163 & $\begin{array}{l}\text { Choroid (85.9) } \\
\text { CB \& iris (14.1) }\end{array}$ & Japanese (100) & 63.5 \\
\hline
\end{tabular}

CB: ciliary body; COMS: Collaborative Ocular Melanoma Study

Table III. Clinical characteristics of five patients with melanoma-related metastasis.

\begin{tabular}{|c|c|c|c|c|c|c|c|}
\hline Case & $\begin{array}{l}\text { Primary } \\
\text { treatment }\end{array}$ & Histology & $\begin{array}{l}\text { Relapse-free } \\
\text { survival (mth) }\end{array}$ & $\begin{array}{l}\text { Site of } \\
\text { metastasis }\end{array}$ & Adjuvant therapy & $\begin{array}{l}\text { Current } \\
\text { status }\end{array}$ & $\begin{array}{l}\text { Overall } \\
\text { survival* (mth) }\end{array}$ \\
\hline 1 & Enucleation & Epithelioid & 0 & Hepatic & None & Deceased & 1 \\
\hline 3 & Enucleation & Mixed & 22 & $\begin{array}{l}\text { Hepatic } \\
\text { Peritoneal }\end{array}$ & Imatinib & Deceased & 1 \\
\hline 4 & Enucleation & $\begin{array}{l}\text { Cytomorphology } \\
\text { not discernible from } \\
\text { necrotic tumour }\end{array}$ & 99 & Peritoneal & Imatinib & Deceased & 1 \\
\hline 5 & Enucleation & Spindle & 267 & Pulmonary & Pulmonary metastectomy & Alive & 55 \\
\hline
\end{tabular}

*Overall survival from time of diagnosis of metastasis.

expression profile in Chinese patients, and this is discussed in greater detail below. Notably, all patients with UM in our series had CM.

A major limitation of our study is the relatively small series of patients, given that UM is not common in Chinese and Asian Indian patients. In more than half of the patients referred to our centre, the diagnosis of CM was made only after a period of followup. We acknowledge that it is sometimes difficult to diagnose UM due to various factors. These include its relative rarity in Asians, the unfamiliarity with this entity among treating physicians, the varied and occasionally atypical clinical manifestations, and the inability to rule out other benign differential diagnosis with certainty. ${ }^{(21)}$ Nonetheless, ophthalmologists should (a) be mindful of potentially avoidable delays such as the failure to detect a tumour during ophthalmoscopy; (b) be familiar with the typical characteristics of UM on standardised A-scans and fluorescein angiography; (c) be alert to possible misdiagnosis as naevus or macular degeneration; and (d) be vigilant to follow up on a suspicious naevus. ${ }^{(22)}$ The diagnosis of UM is ultimately clinical, but most ophthalmologists practising in Asia have limited clinical experience with this rare tumour and may find it a diagnostic challenge even with a high clinical suspicion. Therefore, it is important to make an early referral to an ocular oncologist who can provide diagnostic support and appropriate treatment.

Another limitation of our study is the limited genetic testing results and staging based on the American Joint Committee on 
Cancer system. Gene expression profiling has advanced our understanding of the pathobiology of $U M$, with mutations in GNAQ/GNA11 implicated as an early event in tumorigenesis that causes increased proliferation, leading to a low-grade, premalignant melanocytic tumour. ${ }^{(2)}$ The overall frequency of GNAQ/ GNA11 mutations in different populations is variable. Analyses of UM from Dutch, American, Japanese, Greek and Chinese populations reveal a frequency of GNAQ/GNA11 mutations of $93.4 \%{ }^{(23)} 83.0 \%,^{(24)} 57.9 \%,{ }^{(25)} 42.4 \%{ }^{(26)}$ and $38.0 \%$, ${ }^{(27)}$ respectively. The frequency of GNAQ/GNA11 mutations in the South Indian population has not been reported. Identifying the key driver mutations in UM in the Chinese and Asian Indian populations would be interesting, especially in light of their earlier age at presentation.

Metastatic disease developed in $45.5 \%$ of our patients, with a mean metOS of 19.8 months from diagnosis of metastasis (Table III). In one patient with metastasis who underwent genetic testing, monosomy 3 was identified. As metastatic disease is almost universally fatal, the ability to identify patients at high risk of metastasis is imperative for prognostication and selection of suitable patients for therapeutic interventional studies to alter the natural history of the disease. The chromosomal mutations that have been identified as having the greatest impact on melanomarelated metastases are $8 p$ loss (hazard ratio [HR] 21.51, $p<0.001$ ), $8 q$ gain $(\mathrm{HR}$ 9.77, $\mathrm{p}<0.001)$ and complete monosomy 3 (HR 6.68, $\mathrm{p}<0.001)^{.12)}$ Loss of BAP1 has also been implicated as a metastasis-related mutation, ${ }^{(11)}$ and SF3B1 mutations are associated with late metastasis. ${ }^{(28)}$ In contrast, EIF1AX-mutated tumours are associated with prolonged survival and low metastatic risk. ${ }^{(28)}$ The spectrum of disease mutations in metastasising UM is rapidly expanding. Going forward, the emerging challenge is practical clinical application of these genetic prognostic factors to risk stratify and individualise surveillance protocols for early detection of metastasis, and discern if selected patients may benefit from prophylactic adjuvant systemic therapy to prevent metastasis.

In conclusion, there is preliminary evidence to suggest that the clinicopathologic spectrum of UM in the Chinese and Asian Indian populations may be distinct, given their earlier age of onset. Further, the lower frequency of GNAQ/11 mutations identified in Chinese patients raises the possibility that the key driver mutations may differ in different populations. For this uncommon tumour, an approach using a regional registry replete with information on the gene expression profile will be invaluable in understanding the disease spectrum in the Southeast Asian population, and will also enable individualised treatment to improve long-term survival. The optimal management of UM is increasingly complex, and an ocular oncology centre is indispensable in ensuring patients with this tumour can receive the highest possible standard of care.

\section{ACKNOWLEDGEMENT}

The above study was presented by the corresponding author at the Singapore APAO (2017) Ocular Oncology - Melanoma Session.

\section{REFERENCES}

1. Singh AD, Topham A. Survival rates with uveal melanoma in the United States: 1973-1997. Ophthalmology 2003; 110:962-5.

2. Harbour JW, Chao DL. A molecular revolution in uveal melanoma: implications for patient care and targeted therapy. Ophthalmology 2014; 121:1281-8.

3. Werdich XQ, Jakobiec FA, Singh AD, Kim IK. A review of advanced genetic testing for clinical prognostication in uveal melanoma. Semin Ophthalmol 2013; 28:361-71.

4. Diener-West M, Reynolds SM, Agugliaro DJ, et al; Collaborative Ocular Melanoma Study Group. Development of metastatic disease after enrollment in the COMS trials for treatment of choroidal melanoma: Collaborative Ocular Melanoma Study Group Report No. 26. Arch Ophthalmol 2005; 123:1639-43.

5. Singh AD, Turell ME, Topham AK. Uveal melanoma: trends in incidence, treatment, and survival. Ophthalmology 2011; 118:1881-5.

6. Park SJ, Oh CM, Kim BW, et al. Nationwide incidence of ocular melanoma in South Korea by using the national cancer registry database (1999-2011). Invest Ophthalmol Vis Sci 2015; 56:4719-24.

7. Stang A, Parkin DM, Ferlay J, Jöckel KH. International uveal melanoma incidence trends in view of a decreasing proportion of morphological verification. Int J Cancer 2005; 114:114-23.

8. Shields CL, Kaliki S, Cohen MN, et al. Prognosis of uveal melanoma based on race in 8100 patients: The 2015 Doyne Lecture. Eye (Lond) 2015; 29:1027-35.

9. The Collaborative Ocular Melanoma Study (COMS) randomized trial of pre-enucleation radiation of large choroidal melanoma I: characteristics of patients enrolled and not enrolled. COMS report no. 9. Am J Ophthalmol 1998; 125:767-78.

10. Zuidervaart W, van Nieuwpoort F, Stark M, et al. Activation of the MAPK pathway is a common event in uveal melanomas although it rarely occurs through mutation of BRAF or RAS. Br J Cancer 2005; 92:2032-8.

11. Harbour JW, Onken MD, Roberson ED, et al. Frequent mutation of BAP1 in metastasizing uveal melanomas. Science 2010; 330:1410-3.

12. Shields CL, Say EAT, Hasanreisoglu M, et al. Personalized prognosis of uveal melanoma based on cytogenetic profile in 1059 patients over an 8-year period: The 2017 Harry S. Gradle Lecture. Ophthalmology 2017; 124:1523-31.

13. Mortality in patients with small choroidal melanoma. COMS report no. 4. The Collaborative Ocular Melanoma Study Group. Arch Ophthalmol 1997; 115:886-93.

14. Straatsma BR, Fine SL, Earle JD, et al. Enucleation versus plaque irradiation for choroidal melanoma. Ophthalmology 1988; 95:1000-4.

15. Design and methods of a clinical trial for a rare condition: the Collaborative Ocular Melanoma Study. COMS Report No. 3. Control Clin Trials 1993; 14:362-91.

16. Eskelin S, Kivelä T. Mode of presentation and time to treatment of uveal melanoma in Finland. Br J Ophthalmol 2002; 86:333-8.

17. Biswas J, Kabra S, Krishnakumar S, Shanmugam MP. Clinical and histopathological characteristics of uveal melanoma in Asian Indians. A study of 103 patients. Indian J Ophthalmol 2004; 52:41-4.

18. Dhupper M, Biswas J, Gopal L, Kumar SK, Khetan V. Clinicopathological correlation of choroidal melanoma in Indian population: a study of 113 cases. Oman J Ophthalmol 2012; 5:42-5.

19. Liu YM, Li Y, Wei WB, Xu X, Jonas JB. Clinical characteristics of 582 patients with uveal melanoma in China. PLoS One 2015; 10:e0144562.

20. Tomizuka T, Namikawa K, Higashi T. Characteristics of melanoma in Japan: a nationwide registry analysis 2011-2013. Melanoma Res 2017; 27:492-7.

21. Damato EM, Damato BE. Detection and time to treatment of uveal melanoma in the United Kingdom: an evaluation of 2,384 patients. Ophthalmology 2012; 119:1582-9.

22. Ah-Fat FG, Damato BE. Delays in the diagnosis of uveal melanoma and effect on treatment. Eye (Lond) 1998; 12(Pt 5):781-2.

23. Koopmans AE, Vaarwater J, Paridaens D, et al. Patient survival in uveal melanoma is not affected by oncogenic mutations in GNAQ and GNA11. Br J Cancer 2013; 109:493-6.

24. Van Raamsdonk CD, Griewank KG, Crosby MB, et al. Mutations in GNA11 in uveal melanoma. N Engl J Med 2010; 363:2191-9.

25. Ominato J, Fukuchi T, Sato A, et al. The role of mutation rates of GNAQ or GNA11 in cases of uveal melanoma in Japan. Appl Immunohistochem Mol Morphol 2018; 26:658-63.

26. Psinakis F, Katseli A, Koutsandrea C, et al. Uveal melanoma: GNAQ and GNA11 mutations in a Greek population. Anticancer Res 2017; 37:5719-26.

27. Xu X, Wei WB, Li B, et al. Oncogenic GNAQ and GNA11 mutations in uveal melanoma in Chinese. PLoS One 2014; 9:e109699.

28. Yavuzyigitoglu S, Koopmans AE, Verdijk RM, et al; Rotterdam Ocular Melanoma Study Group. Uveal melanomas with SF3B1 mutations: a distinct subclass associated with late-onset metastases. Ophthalmology 2016; 123:1118-28. 